\title{
Metastasis to the Choroid Plexus from Thyroid Cancer: Case Report
}

\author{
Yosuke Kitagawa, ${ }^{1}$ Fumi Higuchi, ${ }^{1}$ Yoshihiro Abe, ${ }^{1}$ Hadzuki Matsuda, ${ }^{1,2}$ \\ Phyo KIM, ${ }^{1}$ and Keisuke UEKI ${ }^{1,3}$
}

Departments of ${ }^{1}$ Neurosurgery, ${ }^{2}$ Pathology, and ${ }^{3}$ Cancer Center, Dokkyo Medical University, Mibu, Tochigi

\begin{abstract}
Thyroid cancer is not a common primary cancer causing intracranial metastasis. Here we report a 74-year-old woman with magnetic resonance imaging (MRI) demonstrating a $4 \mathrm{~cm}$ round, heterogeneously enhancing mass in the trigone of the right lateral ventricle. Systemic screening by computed tomography (CT) examination detected a $20 \mathrm{~mm}$ nodule with calcification in the thyroid, multiple well circumscribed nodules in bilateral lung filed, and a bone metastasis to the right dorsal rib. Cerebral angiography demonstrated a hypervascular mass fed from anterior and posterior choroidal arteries. Tumor biopsy via parietal transcortical approach confirmed a thyroid carcinoma metastasis to the choroid plexus. Of the 33 reported cases of choroid plexus metastasis, $14(42 \%)$ are from kidney and $3(9 \%)$ from thyroid cancer, which appears to be overrepresented considering their prevalence among all brain metastasis. There may be seed-and-soil relationship between thyroid cancer and choroid plexus.
\end{abstract}

Key words: brain metastasis, intraventricular tumor, choroid plexus, seed-and-soil phenomenon

\section{Introduction}

The vast majority of intracranial cancer metastasis occurs in the brain parenchyma, and metastasis to choroid plexus is rare. Common pure intraventricular tumors are meningiomas and choroid plexus papillomas/carcinomas, and metastasis is not ranked high on the list of differential diagnosis. Here we report a metastatic tumor to the choroid plexus from a thyroid cancer, which is not a common cause of intracranial metastasis.

\section{Case Report}

A 74-year-old woman with a history of hypertension but not of any malignancy presented with vertigo, memory loss, and clumsiness in the left hand that had gradually worsened by 2 months. Neurological examination detected no focal neurological deficit. Magnetic resonance imaging (MRI) showed a well demarcated, $4 \mathrm{~cm}$ in diameter, heterogeneously enhancing mass in the right lateral ventricle trigone (Fig. 1). Cerebral angiography demonstrated a hypervascular mass supplied from both anterior and posterior choroidal arteries. A meningioma was suspected, but the heterogeneous enhancement prompted us to

Received June 26, 2012; Accepted November 1, 2012 screen for systemic malignancy by whole body computed tomography (CT) scan that revealed multiple nodules in the lung, a destructive lesion at the right dorsal rib, and a slightly enlarged thyroid gland with calcification. Preoperative differential diagnosis included meningioma, choroid plexus carcinoma, and metastasis. Considering the high vascularity of the tumor, open biopsy of the tumor via parietal transcortical approach was performed. The tumor consisted of soft tissue containing yellowish and reddish portions, and caused profuse bleeding when incised. On histological examination, the tumor demonstrated follicular structure containing colloidal substances (Fig. 2). Immunohistochemistry showed that the colloidal substance was positive for thyrogloblin and thyroid transcription factor-1, confirming the diagnosis of thyroid carcinoma metastasis. Considering the general status and the risk of resection of the highly hemorrhagic tumor, the patient underwent local radiation therapy with $60 \mathrm{~Gy}$, and the MRI obtained 1 month after the radiation treatment demonstrated slight shrinkage of the mass. The patient further underwent thyroid tumor resection, followed by systemic radiation therapy using radioactive iodine (RAI). Two months after surgery, MRI of the brain showed enhancement along the biopsy tract suggesting possible dissemination, and $15 \mathrm{~Gy}$ of whole brain radiation therapy was performed. The intraventricular 


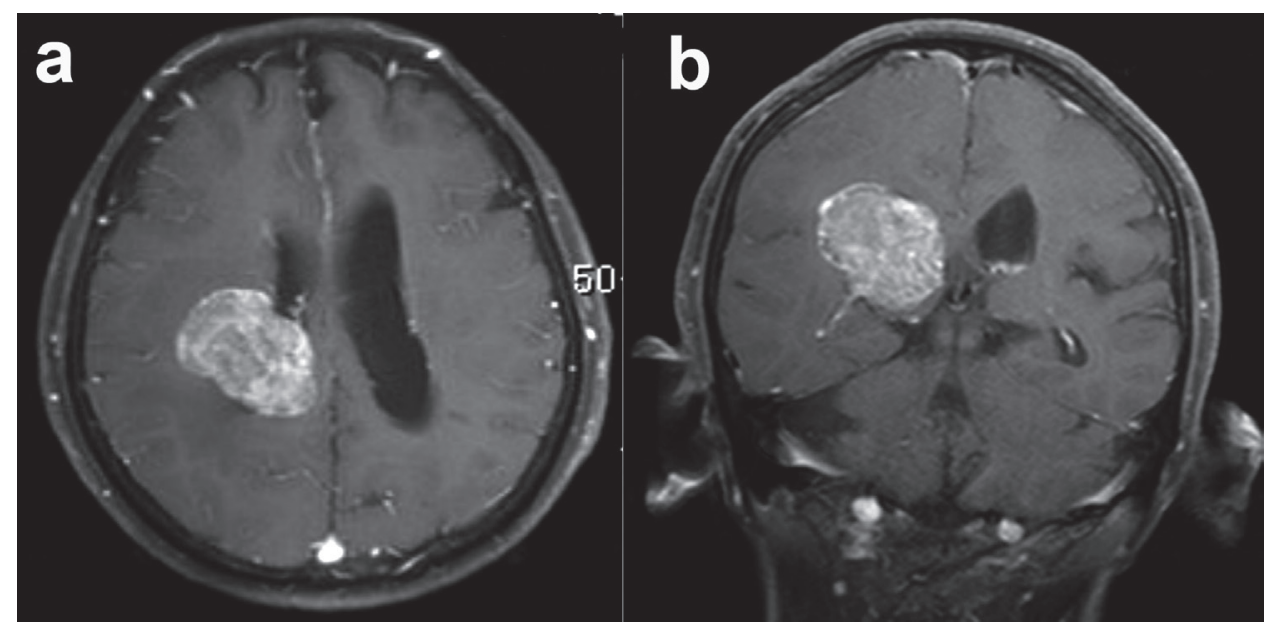

Fig. 1 (a) Axial and (b) coronal view of gadolinium-enhanced magnetic resonance imaging (MRI) demonstrating a well-demarcated tumor within the lateral ventricle.

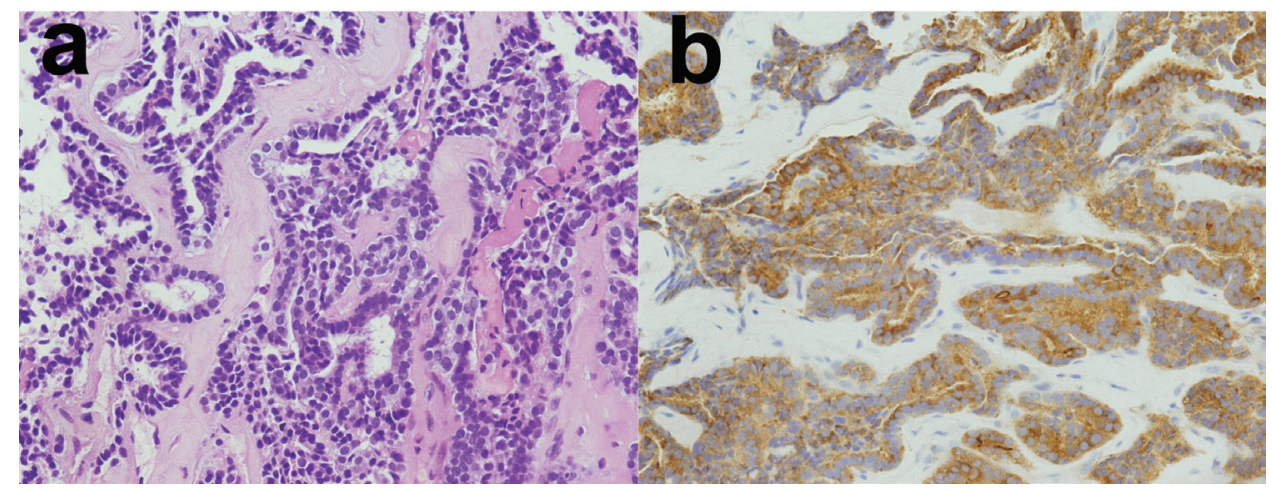

Fig. 2 Microscopic appearance of the tumor. a: Haematoxylin-eosin stain and b: immunohistochemistry for thyroglobulin demonstrate thyroid cancer metastasis.

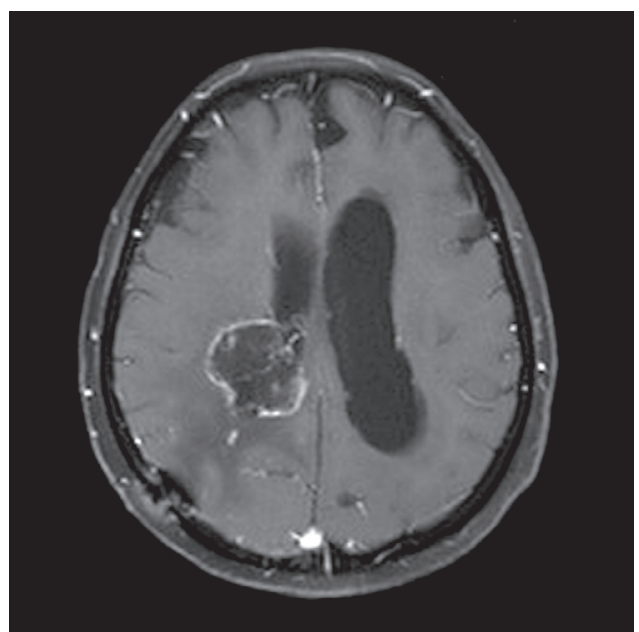

Fig. 3 Gadolinium-enhanced magnetic resonance imaging (MRI) obtained 14 months later demonstrates necrosis of the tumor without growth.

mass gradually lost enhancement, and MRI obtained 14 months after surgery showed complete central necrosis with rim enhancement, with the patient remaining in stable neurologically (Fig. 3).

\section{Discussion}

Thyroid cancer accounts for about $1 \%$ of newly diagnosed malignant neoplasms, of which $94 \%$ are differentiated thyroid cancer of either papillary or follicular type. Both types show relatively benign clinical course with 10-year survival exceeding $80 \%$ and $50 \%$, respectively. When metastasize, the papillarly cancer usually develops lymphogenous metastasis to lymph nodes, while the follicular type mostly causes hematogenous metastasis to lung and bones. Thyroid cancer metastasis to the central nervous system is rare, with only $0.9-1.5 \%$ of brain metastasis being reported to be from the thyroid cancer. ${ }^{3,26,33)}$

In the present case, the tumor was a purely intraventricular mass without obvious attachment to the ventricular wall, and rich blood supply from the anterior and posterior choroidal arteries were observed. Therefore, the choroid plexus was the probable site of the metastasis. Choroid plexus is not a frequent site of the metastasis, and we could find only 33 such cases in the literature (Table 1). ${ }^{1,2,4-14,16-18,20-24,27-33)}$ Of those 33 cases, 14 cases $(42 \%)$ were from kidney, 4 were from colon, and 
$6(18 \%)$ were from lung cancer. Considering that more than $16.3 \%$ of brain metastases are from lung cancer while kidney accounts for only $9.8 \%,{ }^{25)}$ there seems to be clear tendency for kidney cancer to preferentially metastasize to choroid plexus. Similarly, 9\% (3 of 33 including the present case) prevalence of thyroid cancer as the origin of choroid plexus metastasis also suggest that thyroid cancer cells might have some biological affinity to choroid plexus, demonstrating an example of the seed and soil relationship. ${ }^{15)}$ Neurological symptom for those cases are mostly non-localizing, with headache or consciousness disturbance caused by increased intracranial pressure being the common presentation. Probably reflecting the notorious tendency of thyroid cancer for bleeding, intratumoral hemorrhage can be the onset of the symptoms (Table 1). ${ }^{32)}$

Although patients with papillary thyroid cancer can expect 10-year survival of more than $90 \%$, the rate drops to $30 \%$ to $50 \%$ in patients with lung metastasis. For those with brain metastasis, median survival is reported to be only 12.4 months. ${ }^{19,26)}$ McWilliams et al. studied the cases of 16 patients with brain metastasis from thyroid cancer, and reported that surgical resection of the brain lesion was associated with longer survival (20.8 months vs 2.7 months ). ${ }^{19)}$ Addition of stereotactic radiosurgery to the residual tumor after partial surgical

Table 1 Summary of 33 cases of matastasis to the choroid plexus

\begin{tabular}{|c|c|c|c|c|}
\hline Author (year) & Age/Sex & Primary & Location & Presenting symtoms \\
\hline Killebrew et al. (1983) ${ }^{12)}$ & $55 / F$ & Kidney & L. trigone & headache \\
\hline Kendal et al. (1983) & $? / \mathrm{F}$ & Breast & R. trigone & \\
\hline Kendal et al. (1983) & $? / \mathrm{F}$ & Skin & 4th ventricle & \\
\hline Kart et al. (1986) ${ }^{10)}$ & $61 / \mathrm{M}$ & Lung & L. trigone & \\
\hline Shigemori et al. $(1987)^{27)}$ & $58 / \mathrm{M}$ & Kidney & Body of R.LV & headache \\
\hline Fukui et al. $(1990)^{6)}$ & $53 / \mathrm{F}$ & Lymphoma & R. trigone & headache \\
\hline Tanimoto et al. $(1991)^{31)}$ & $64 / \mathrm{M}$ & Lung & R. trigone & headache \\
\hline Mizuno et al. (1992) & $59 / \mathrm{M}$ & Kidney & Body of L.LV & headache \\
\hline Nakabayashi et al. (1994) 22$)$ & $64 / \mathrm{M}$ & Stomach & Body of L.LV & consiousness dist. \\
\hline Suetake et al. (1994) & $78 / \mathrm{M}$ & Kidney & Body of L.LV & consiousness dist. \\
\hline Spetzger et al. (1995) & $60 / \mathrm{F}$ & Kidney & 4th ventricle & headache \\
\hline Kohno et al. $(1996)^{14)}$ & $66 / \mathrm{M}$ & Kidney & R. trigone & $\begin{array}{l}\text { hemiparesis. } \\
\text { disorientation }\end{array}$ \\
\hline Kohno et al. (1996) & $66 / \mathrm{M}$ & Lung & R. inferior horn & seizures \\
\hline Kohno et al. (1996) & $45 / \mathrm{M}$ & Colon & L. trigone & hemiparesis \\
\hline Matsumura et al. (1997) & $68 / \mathrm{M}$ & Kidney & Body of R.LV & headache \\
\hline Raila et al. (1998) ${ }^{24)}$ & $47 / \mathrm{F}$ & Kidney & R. trigone & headache \\
\hline Arbelaez et al. (1999) ${ }^{2)}$ & $48 / \mathrm{F}$ & Skin & L. trigone & headache \\
\hline Iwatsuki et al. (1999) ${ }^{8)}$ & $75 / \mathrm{F}$ & Kidney & L. trigone & $\begin{array}{l}\text { headache, } \\
\text { consiousness dist. }\end{array}$ \\
\hline Qasho et al. (1999) ${ }^{23)}$ & $40 / \mathrm{M}$ & Bladder & R. trigone & seizures \\
\hline Ai-Anazi et al. $(2000)^{1)}$ & $81 / \mathrm{M}$ & Colon & Bil ventriclars & headache \\
\hline Motoyama et al. (2000) ${ }^{21)}$ & $70 / F$ & Kidney & L. trigone & headache \\
\hline Escott et al. $(2001)^{5)}$ & $32 / \mathrm{M}$ & Skin & L. trigone & headache \\
\hline Hillard et al. $(2003)^{7)}$ & $54 / \mathrm{F}$ & Kidney & L. trigone & headache \\
\hline Kitajima et al. (2003) ${ }^{13)}$ & $48 / \mathrm{F}$ & Colon & R. ineror horn & headache \\
\hline Kadrian et al. $(2004)^{9)}$ & $54 / F$ & Kidney & L. trigone & headache \\
\hline Leach et al. $(2004)^{17)}$ & $50 / \mathrm{F}$ & Colon & 3rd ventricle & headache \\
\hline Leach et al. (2004) & $43 / \mathrm{F}$ & Kidney & 3rd ventricle & $\begin{array}{l}\text { personality \& } \\
\text { behavioral changes }\end{array}$ \\
\hline Lauretti et al. $(2005)^{16)}$ & $65 / \mathrm{F}$ & Kidney & Body of R.LV & headache \\
\hline Sung et al. $(2006)^{30)}$ & $42 / \mathrm{M}$ & Esophagus & 3rd ventricle & unsteady gait \\
\hline Zang et al. (2009) ${ }^{33)}$ & $62 / \mathrm{M}$ & Thyroid & R. trigone & memory loss \\
\hline Della Puppa et al. (2010) & $66 / F$ & Breast & L. trigone & aphasia \\
\hline Wasita et al. $(2010)^{32)}$ & $75 / \mathrm{M}$ & Thyroid & Body of R.LV & headache \\
\hline Present case (2012) & $74 / \mathrm{F}$ & Thyroid & R. trigone & memory loss \\
\hline
\end{tabular}

LV: lateral ventricle. 
resection improved the prognosis (31.3 months vs 12.8 months). Administration of RAI was also effective while the benefit was rather marginal (18.4 months with RAI and 13.6 months without RAI). ${ }^{33)}$ When the lesion was resected, there was no clear benefit of whole brain radiation therapy. Therefore, when feasible, total resection of the lesion is the treatment of choice for thyroid cancer metastasis to the brain. In our case, however, the large size, location, and the hypervascularity of the lesion led to the decision to perform biopsy and radiation therapy to follow.

In summary, we reported a large ventricular tumor caused by thyroid cancer metastasis to the choroid plexus. Choroid plexus metastasis is a rare event and the number of reported cases is still small, but kidney and thyroid cancer seems to have higher tendency to metastasize to choroid plexus and hence should be included in the list of differential diagnosis when such lesions are encountered.

\section{Conflicts of Interest Disclosure}

The authors have no personal, financial, or institutional interest in any of the drugs, materials, or devices described in this article.

\section{References}

1) Al-Anazi A, Shannon P, Guha A: Solitary metastasis to the choroid plexus. Case illustration. J Neurosurg 92: 506, 2000

2) Arbelaez A, Castillo M, Armao DM: Imaging features of intraventricular melanoma. AJNR Am J Neuroradiol 20: 691-693, 1999

3) Chiu AC, Delpassand ES, Sherman SI: Prognosis and treatment of brain metastases in thyroid carcinoma. J Clin Endocrinol Metab 82: 3637-3642, 1997

4) Della Puppa A, Dal Pos S, Zovato S, Orvieto E, Ciccarino P, Manara R, Zustovich F, Berti F, Gardiman MP, Scienza R: Solitary intra-ventricular brain metastasis from a breast carcinoma. J Neurooncol 97: 123-126, 2010

5) Escott EJ: A variety of appearances of malignant melanoma in the head: a review. Radiographics 21: 625-639, 2001

6) Fukui K, Okamura K, Watanabe M, Nakamura S, Yamamoto M, Nagatani T, Oyama H, Itou M: [Choroid plexus involvement in malignant lymphoma. Case report]. Neurol Med Chir (Tokyo) 30: 869-873, 1990 (Japanese)

7) Hillard VH, Musunuru K, Hasan I, Zia S, Hirschfeld A: Long-term management of bilateral metastases of renal cell carcinoma to the choroid plexus. Acta Neurochir (Wien) 145: 793-797, 2003

8) Iwatsuki K, Sato M, Taguchi J, Fukui T, Kiyohara H, Yoshimine T, Hayakawa T: [Choroid plexus metastasis of renal cell carcinoma causing intraventricular hemorrhage: a case report]. No Shinkei Geka 27: 359-363, 1999 (Japanese)

9) Kadrian D, Tan L: Single choroid plexus metastasis 16 years after nephrectomy for renal cell carcinoma: case report and review of the literature. J Clin Neurosci 11: 88-91, 2004

10) Kart BH, Reddy SC, Rao GR, Poveda H: Choroid plexus metastasis: CT appearance. J Comput Assist Tomogr 10: 537-540, 1986

11) Kendall B, Reider-Grosswasser I, Valentine A: Diagnosis of masses presenting within the ventricles on computed tomography. Neuroradiology 25: 11-22, 1983

12) Killebrew K, Krigman M, Mahaley MS, Scatliff JH: Metastatic renal cell carcinoma mimicking a meningioma. Neurosurgery 13: 430-434, 1983

13) Kitajima K, Morita M, Morikawa M, Sugimura K: Choroid plexus metastasis of colon cancer. Magn Reson Med Sci 2: 155-158, 2003

14) Kohno M, Matsutani M, Sasaki T, Takakura K: Solitary metastasis to the choroid plexus of the lateral ventricle. Report of three cases and a review of the literature. J Neurooncol 27: 47-52, 1996

15) Langley RR, Fidler IJ: The seed and soil hypothesis revisited-the role of tumor-stroma interactions in metastasis to different organs. Int J Cancer 128: 2527-2535, 2011

16) Lauretti L, Fernandez E, Pallini R, Massimi L, Albanese A, Denaro L, Maira G: Long survival in an untreated solitary choroid plexus metastasis from renal cell carcinoma: case report and review of the literature. J Neurooncol 71: 157-160, 2005

17) Leach JC, Garrott H, King JA, Kaye AH: Solitary metastasis to the choroid plexus of the third ventricle mimicking a colloid cyst: a report of two cases. J Clin Neurosci 11: 521-523, 2004

18) Matsumura $H$, Yoshimine $T$, Yamamoto $S$, Maruno M, Hayakawa T, Ono Y, Kondoh N, Namiki M: Single solitary metastasis of the slowly progressive type of renal cell carcinoma to the choroid plexus-case report. Neurol Med Chir (Tokyo) 37: 916-919, 1997

19) McWilliams RR, Giannini C, Hay ID, Atkinson JL, Stafford SL, Buckner JC: Management of brain metastases from thyroid carcinoma: a study of 16 pathologically confirmed cases over 25 years. Cancer 98: 356-362, 2003

20) Mizuno M, Asakura K, Nakajima S, Sampei T, Sayama I, Kawamura S, Yasui N, Fukazawa H: [Renal cell carcinoma metastasizing to choroid plexus of lateral ventricle; a case report]. No Shinkei Geka 20: 469-474, 1992 (Japanese)

21) Motoyama $Y$, Nabeshima S, Yamazoe N, Isaka F, Higuchi K, Satow T: [A case of choroid plexus metastasis with intracerebral hemorrhage from renal cell carcinoma]. Jpn J Neurosurg 9: 753-757, 2000 (Japanese)

22) Nakabayashi H, Murata K, Sakaguchi M, Nakajima K, Katsuyama $\mathrm{J}$ : Choroid plexus metastasis from gastric cancer-case report. Neurol Med Chir (Tokyo) 34: 183-186, 1994

23) Qasho R, Tommaso V, Rocchi G, Simi U, Delfini R: Choroid plexus metastasis from carcinoma of the bladder: case report and review of the literature. J Neurooncol 45: 237-240, 1999

24) Raila FA, Bottoms WT, Fratkin JD: Solitary choroid plexus metastasis from a renal cell carcinoma. South Med J 91: 1159-1162, 1998

25) Schouten LJ, Rutten J, Huveneers HA, Twijnstra A: Incidence of brain metastases in a cohort of patients with carcinoma 
of the breast, colon, kidney, and lung and melanoma. Cancer 94: 2698-2705, 2002

26) Sherman SI: Thyroid carcinoma. Lancet 361: 501-511, 2003

27) Shigemori M, Shimamoto H, Noguchi S, Yoshitake Y, Sugita Y, Kuramoto S: [Choroid metastasis of renal cell carcinoma]. Progress in computerized tomography 9: 603-606, 1987 (Japanese)

28) Spetzger U, Mull M, Sure U, Gilsbach J: Subarachnoid and intraventricular hemorrhage caused by hypernephroma metastasis, accompanied by innocent bilateral posterior communicating artery aneurysms. Surg Neurol 44: 275-278, 1995

29) Suetake K, Shinya T, Takeda M: [A choroid plexus metastasis of a renal cell carcinoma: a case report]. Jpn J Neurosurg 3: 436-441, 1994 (Japanese)

30) Sung WS, Dubey A, Erasmus A, Hunn A: Solitary choroid plexus metastasis from carcinoma of the oesophagus. J Clin Neurosci 15: 594-597, 2008
31) Tanimoto M, Tatsumi S, Tominaga S, Kamikawa S, Nagao T, Tamaki N, Matsumoto S: Choroid plexus metastasis of lung carcinoma-case report. Neurol Med Chir (Tokyo) 31: 152-155, 1991

32) Wasita B, Sakamoto M, Mizushima M, Kurosaki M, Watanabe T: Choroid plexus metastasis from papillary thyroid carcinoma presenting with intraventricular hemorrhage: case report. Neurosurgery 66: E1213-1214, 2010

33) Zhang YA, Kavar B, Drummond KJ: Thyroid carcinoma metastasis to the choroid plexus of the lateral ventricle. J Clin Neurosci 16: 118-121, 2009

Address reprint requests to: Keisuke Ueki, MD, Department of Neurosurgery and Cancer Center, Dokkyo Medical University, Kitakobayashi 880, Mibu, Tochigi 321-0293, Japan. e-mail: kueki-tky@umin.ac.jp 